$\Omega$

Fernando Gamarra, Julie-Lyn Noël, Alessandro Brunelli,

Anne-Marie C. Dingemans, Enriqueta Felip, Mina Gaga,

Bogdan Dragos Grigoriu, Georgia Hardavella, Rudolf M. Huber,

Samuel Janes, Gilbert Massard, Paul Martin Putora,

Jean-Paul Sculier, Philipp A. Schnabel, Sara Ramella,

Dirk Van Raemdonck, Anne-Pascale Meert

(1)

For a full list of affiliations please see the Acknowledgements section.

\title{
Thoracic oncology HERMES: European curriculum recommendations for training in thoracic oncology
}

\section{Introduction}

The HERMES (Harmonising Education in Respiratory Medicine for European Specialists) project is funded by the European Respiratory Society (ERS) and has the declared aims of harmonising education in thoracic medicine, recognising diplomas and certificates of qualification, and improving free access and mobility for medical specialists across the European Union (EU). This takes into account Directive 2013/55/EU of the European Parliament and of the Council [1] on the recognition of professional qualifications, one of the pillars of EU legislation. Moreover, it conforms to the fact that there is a shortage of medical/surgical specialists in several European countries, which means that more physicians of other European and non-European countries will be needed to sustain the functioning and development of health services in future years and decades [2]. HERMES is working towards the development of harmonised and structured programmes for education across respiratory specialties to ensure that the best care is delivered for those suffering from respiratory diseases.

\section{Thoracic oncology}

Thoracic oncology is a growing discipline. Important progress has been seen in the understanding of the pathophysiological mechanisms of lung cancer. This has led to the development of several innovative diagnostic and therapeutic strategies in the past decade. Nowadays, the diagnosis and treatment of thoracic malignancies require the collaboration of different specialists like respiratory physicians, medical oncologists, radiation oncologists and thoracic surgeons, together with chest radiologists, pathologists, palliative care specialists and other allied health specialties. Additional training will make these specialists more efficient in their interaction with the patients and fellow physicians. Some experts advocate that treatment of patients with thoracic tumours should be concentrated in specialised centres in which all the involved specialties are available. These specialists will need to be certified for their competence. As for other malignancies, it is required that treatment options for each patient are discussed in a tumour board by a multidisciplinary team [3].
Cite as: Gamarra F, Noël J-L, Brunelli A, et al. Thoracic oncology HERMES: European curriculum recommendations for training in thoracic oncology. Breathe 2016; 12: 249-255 
Training for thoracic oncology is not well defined in most European countries. The Thoracic oncology HERMES Task Force aims to accomplish a training and certification programme, and accreditation that should be accessible to all physicians involved in the diagnosis and treatment of thoracic malignancies. The certificate should be recognised by all European countries. Moreover, this should be a contribution to the improvement of the thoracic oncology standard of care. The Task Force is part of the "Thoracic Oncology Action Plan" [4] that also includes the Task Force for a European initiative for quality management in lung cancer care [5]. The thoracic oncology HERMES syllabus was published in September 2013 and was the first syllabus written together by authors of all treating disciplines $[6,7]$.

\section{Contemporary concepts of medical education}

The Task Force strived to develop a curriculum which would be a good basis for the development of structured educational programmes in thoracic oncology whether delivered by the ERS, other societies and/or local institutions. In order to achieve this, current concepts of medical education were reflected upon by the Task Force at each step in the completion of the curriculum. Thoracic oncology training was considered to be interprofessional, as well as a multidisciplinary, training. The Task Force adopted the UK-based Centre for Advancement of Interprofessional Education definition of interprofessional education as occasions when two or more professions learn from, with and about each other to improve collaboration and the quality of care [8]. Furthermore, it was kept in mind that effective learning within multidisciplinary teams comes from certain behaviour which includes: 1) understanding and respecting the roles and expertise of health and social care professionals in the context of working and learning as a multi-professional team; and 2) understanding the contribution that effective interdisciplinary team work is the mainstay to the delivery of safe and high-quality care, as was declared by the General Medical Council in 2009 [9]. The objectives of interprofessional education were also considered according to BLUTEAU and JACKSON [10]: "modify reciprocal attitudes, establish common values, knowledge and skills, build teams, solve problems, respond to community needs, change practice and change the professions". The definition of the curriculum by HARDEN [11] was also considered as it best fits their aims. The curriculum is a sophisticated blend of educational strategies, course content, learning outcomes, educational experiences and assessment while taking into account the educational environment, the individual's learning style, personal timetable and programme of work. Thus, students can identify what, when, where and how they can learn. The Task Force aimed to make the scope and sequence of dedicated learning more explicit and link learning outcomes with relevant assessments, hence curriculum planning becomes more effective and efficient [11].

\section{Aims of the thoracic oncology curriculum Task Force}

The curriculum is the next milestone after the development of the syllabus. Thus, we aimed to specify the learning outcomes for each syllabus item, present training and assessment recommendations, define the duration of the training and determine who will be eligible for the training. By defining levels of assessment, we aimed to orientate the learners to the level of exposure needed to acquire expertise and certification in thoracic oncology.

\section{Roles of Task Force participants}

The Thoracic oncology HERMES Task Force is led by two chairs, A-P. Meert (Belgium) and F. Gamarra (Germany), and a medical education specialist (J-L. Noël, Switzerland) who coordinated the activities of the group. The other members were chosen to represent the following treating medical disciplines involved in thoracic oncology: respiratory medicine, medical oncology, radiation oncology and thoracic surgery. Respiratory physicians and medical oncologists who are active members of the ERS were involved and include: M. Gaga (Greece), B.D. Grigoriu (Romania), R. Huber (Germany), S. Janes (UK) and J-P. Sculier (Belgium). The junior members of the ERS Thoracic Oncology Assembly were represented by G. Hardavella (UK). Furthermore, we included a pathologist (P.A. Schnabel, Germany) who specialised in thoracic tumours. The Task Force also collaborated with other European societies. G. Massard (France), D. Van Raemdonck (Belgium) and A. Brunelli (UK) participated as official representatives of European Society of Thoracic Surgeons, and S. Ramella (Italy) and P.M. Putora (Switzerland) represented European Society of Thoracic Radiotherapy and Oncology. E. Felip (Spain) and A-M.C. Dingemans (the Netherlands) were chosen as medical oncology specialists appointed by the European Society for Medical Oncology. In order to account for the different standards in Europe the Task Force members were chosen to represent as many European regions as possible.

The national respondents consist of experts nominated by the Forum of European Respiratory Societies in 2011 and the national coordinators of the European quality management in lung cancer care [6]. At the start during the syllabus development they were expert respondents in the Delphi process. At this phase of curriculum 
development they gave valuable feedback and validated the content.

\section{Processes in curriculum development}

The methodology follows that of the other HERMES projects and is in continuous development. The syllabus had been defined as a list of topics that learners should study on the subject of thoracic oncology. The curriculum elaborates the syllabus content and should further specify for each topic the learning outcomes, the levels of competence and minimum clinical or learning exposure and give recommendations for assessment tools. Therefore, the curriculum is based on the already published thoracic oncology syllabus [6].

Working groups of thoracic oncology experts were formed and took charge of writing the content of the curriculum modules. They were provided with a template with the common format used in other HERMES projects together with instructions on how to complete the module which included the following. 1) Information on Bloom's taxonomy of learning domains with a list of verbs to be used according to the complexity of the learning items [12, 13]. 2) A list of possible teaching and learning methods [14]. 3) Information on the model of competence by MILLER [15] and its different levels. 4) A list of assessment methods currently used in medical education [16].

The first drafts were then reviewed by medical education specialists with a main focus on educational terminology. The evolving versions were then discussed during several plenary sessions that were held from November 2014 to September 2015. During these meetings, the methodological aspects were clarified and the minimum duration of the training together with the intensity of clinical exposure were determined. Furthermore, the Task Force agreed on the assessment methods that were considered realistic and acceptable. Each of the modules was discussed during the plenary meetings until a consensus was reached in all aspects.

The finalised curriculum was sent to medical education specialists and the national respondents, who have participated in the syllabus development since in December 2015. There was a general positive feedback on the curriculum recommendations. Minor comments were received that mainly involved the clarification of used terms. They were incorporated and improved the curriculum content.

\section{The thoracic oncology curriculum}

The final version of the curriculum was completed in December 2015 and can be found in the supplementary material. Box 1 shows the 22 curriculum modules.

In the understanding of the Task Force, thoracic oncology specialists are well experienced clinicians who treat thoracic tumours in a specialised centre. They are mainly respiratory physicians, medical oncologists, radiation oncologists or thoracic surgeons. Additionally, they have a well-founded knowledge about the collaborating disciplines that permits them to understand and appreciate their contribution to the treatment of thoracic tumours. Thoracic oncology specialists are therefore in a position to lead a multidisciplinary thoracic oncology team and chair the tumour board.

Accordingly, the Task Force decided that a prerequisite to complete training is to be a specialist in a discipline that is involved in the treatment of thoracic tumours and to have a recognised certificate in the country in which the applicant is currently working. The question of including other medical specialties such as pathology or palliative care was discussed. It was agreed that medical and surgical specialists who are actively involved in patient treatment are in a position to lead the tumour board or multidisciplinary team meeting and, therefore, are basically eligible. Because this may vary from country to country, it was decided not to have a mandatory list of eligible specialties; thus, training should be interprofessional and multidisciplinary, post-specialty and part of continuing professional development leading to an additional post-specialty certificate attesting to advanced expertise.

\section{Box 1 Thoracic oncology curriculum modules}

1 General principles of the biology of thoracic cancers

2 Aetiology and epidemiology

3 Clinical presentations

4 Diagnostic procedures

5 Imaging

6 Diagnostic and interventional bronchoscopy techniques and medical thoracoscopy

7 Clinical and pathological staging

8 Pathology of intrathoracic tumours

9 Prognostic factors/predictive markers

10 Principles of thoracic surgery

11 Management of surgical complications

12 Principles of radiation therapy

13 Principles of systemic therapy

14 Side-effects of systemic therapy and their management

15 Combined modality treatments

16 Management of particular groups of patients

17 Treatment evaluation and follow-up

18 Supportive care

19 Methodologies for clinical practice and research

20 Ethics

21 Cancer-related immunology

22 Quality and economic considerations in lung cancer treatment 
Table 1 shows the learning outcomes of module 18. The learning outcomes are divided into three domains: 1) knowledge (cognitive skills); 2) skills (psychomotor skills); and 3) attitudes (affective skills). It was decided to include these three learning domains as a physician needs all of them in order to work independently and interact with patients. The differentiation is important in order to emphasise that the training is not only limited to acquiring knowledge, but also honing skills and acquiring the right attitude. For example, "pain management" in module 18 (Supportive care) where complex and exhaustive knowledge on indications, mode of action of drugs and other available techniques is required. But at the same time, the learner needs to be able to collect information on the patient's pain, conduct physical examination and order the corresponding therapy (psychomotor skills). Moreover, the learner will need to display empathy and sensitivity to patients and families, and collaborate with colleagues from other disciplines (affective skills).

To differentiate between different levels of complexity, Bloom's taxonomy of educational objectives was used [13]. It provides a readymade list of action verbs that are classified according to six levels of increasing cognitive complexity: knowledge, comprehension, application, analysis, synthesis and evaluation. The levels of psychomotor skills were imitation, manipulation, precision, articulation and naturalisation. For the affective domain three levels were distinguished: personal, professional and ethical.

Table 2 shows the second half of the curriculum. In this section of the curriculum the Task Force gives suggestions for teaching and learning opportunities that should orient the learners and trainers on how to learn or acquire a specific skill or how to prepare a training programme. For interprofessional education teaching and learning, SWANWICK [14] suggested the following methods to be effective: case-based learning, simulation, shadowing and clinical work in teams, which were considered by the Task Force.

The recommendations for assessment tools and their corresponding level of assessment are also presented in table 1 . The items depict the possible assessment tools that can be used and their corresponding level, according to the pyramid of MILLER [15], and where such an assessment can take place. Figure 1, which is based on the studies of MILLER [15] and AMIN et al. [16], served as a guide in completing these recommendations. Each module has prescribed the overall competency required of the learner. These have been composed considering the

Table 1 Symptom control and complication care: learning outcomes of module 18

\begin{tabular}{|c|c|c|c|}
\hline Syllabus items & Knowledge & Skills & Attitude \\
\hline \multirow[t]{6}{*}{$\begin{array}{l}\text { Pain } \\
\text { management }\end{array}$} & $\begin{array}{l}\text { Discuss indications and timing for specific } \\
\text { management }\end{array}$ & $\begin{array}{l}\text { Conduct physical examination } \\
\text { and interpret findings }\end{array}$ & $\begin{array}{l}\text { Accepts the importance of } \\
\text { multimodal pain management }\end{array}$ \\
\hline & $\begin{array}{l}\text { Recall medications, mode of action, dosing, } \\
\text { recommended and non-recommended } \\
\text { combinations, side-effects and their } \\
\text { management }\end{array}$ & $\begin{array}{l}\text { Manage pain of diverse } \\
\text { aetiology (e.g. neuropathic } \\
\text { pain, complex regional pain } \\
\text { syndrome) }\end{array}$ & \\
\hline & $\begin{array}{l}\text { Describe interventional pain management } \\
\text { techniques (intrathecal, epidural } \\
\text { administration, nerve blocks) }\end{array}$ & $\begin{array}{l}\text { Select opioids and manage } \\
\text { opioid toxicity }\end{array}$ & \\
\hline & $\begin{array}{l}\text { Discuss ablative techniques (radiofrequency, } \\
\text { cryoablation) }\end{array}$ & $\begin{array}{l}\text { Provide end-of-life care related } \\
\text { to pain management }\end{array}$ & \\
\hline & Discuss and list psychosomatic symptoms & & \\
\hline & $\begin{array}{l}\text { Discuss psychological aspects and approaches } \\
\text { to pain management in cancer patients }\end{array}$ & & \\
\hline
\end{tabular}

Table 2 Example of the components listed within the ERS curriculum matrix

\begin{tabular}{cccc}
\hline Teaching and learning opportunities & $\begin{array}{c}\text { Assessment } \\
\text { tools }\end{array}$ & $\begin{array}{c}\text { Level of } \\
\text { assessment }\end{array}$ & Minimum clinical/educational exposure \\
\hline $\begin{array}{c}\text { Case-based discussion of the management } \\
\text { of a lung cancer patient with bone pain }\end{array}$ & $\begin{array}{c}\text { Case-based } \\
\text { discussion }\end{array}$ & 2 & $\begin{array}{c}\text { Discuss and participate in the management of } \\
\text { 20 patients needing supportive care }\end{array}$ \\
\hline
\end{tabular}


knowledge, skills and attitudes prescribed within the module.

In our opinion, there is an opportunity to organise assessments during training at the centre level and therefore a documentation system will need to be established in the form of an e-portfolio.

Finally, minimum clinical or educational exposure is defined. The Task Force suggested minimum full-time training of 12 months in a thoracic oncology centre. The minimum clinical exposure is calculated according to the number of cases expected in a medium-sized centre during this period of time. The rules for the accreditation of training centres are yet to be discussed and will need to be addressed in the future.

\section{Discussion}

To our knowledge this is the most detailed published curriculum for thoracic oncology. It is also the only one that uses contemporary educational methodology. The American Society of Clinical Oncology core curriculum outline came out in 2005. It covers the whole field of medical oncology also including thoracic tumours [17]. The thoracic oncology section is comparable but less detailed than the syllabus jointly published by the ERS in collaboration with other European societies [6]. The International Association for the Study of Lung Cancer has also published an online thoracic oncology global curricular framework that is much less detailed than that of the ERS syllabus [18]. The present thoracic oncology curriculum additionally recommends learning outcomes and educational strategies, such as training opportunities and assessment.

For the present curriculum we applied contemporary concepts of medical education, such as Bloom's taxonomy of learning domains and Miller's model of clinical skills. Medical education specialists guided the correct utilisation of the methods. The curriculum modules are not meant to be read from beginning to end. They are not only directed at learners, but also at teachers planning a thoracic oncology training programme. The curriculum is meant to be used as needed, fit for the context of the learner and trainer. Delivery could be done through a modular training programme where modules can be followed separately or grouped in a track [14].The learners are already trained specialists and have expertise in some modules, e.g. thoracic surgery or radiation therapy, depending on their specialty. The concept was to go beyond the mere list of topics and provide learning outcomes, including the levels of complexity and assessment, in detail for each item. The differentiation of learning outcomes between knowledge, skills and attitudes take into account the fact that working as a physician requires not only knowledge but also motor skills and social

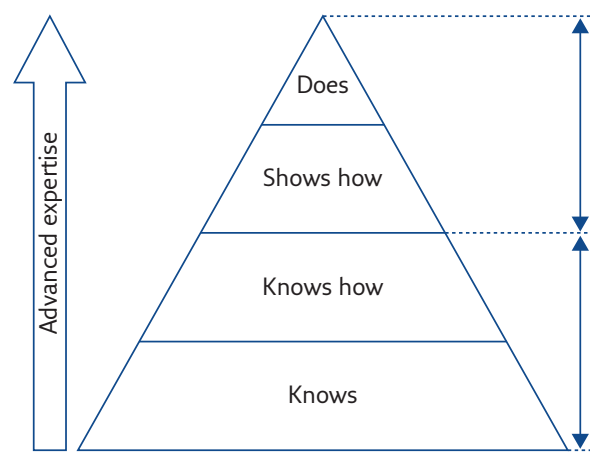

Skills-based assessment: mini clinical evaluation exercise, direct observation of procedural skills, clinical work sampling, checklist, multi-source feedback, logbook, portfolio

Skills-based assessment: long case, short case, structured clinical examination Knowledge-based assessment: case-based discussions, multiple choice questions, extended matching items, key features test

Knowledge-based assessment: oral examination, long essay questions, short answer questions

Figure 1 Miller's model of clinical competence. Reproduced from [15].

competence. The level of performance required for each item is defined by the verbs according to the taxonomy of BLoom [12]. The curriculum gives concrete advice for the development of a training programme including the methods of assessment and the minimum clinical exposure times and patient numbers. The Task Force aligned all these aspects to be congruent during the development of the content [19]. Based on this information, both learners and trainers will be able to appraise what is needed to become a thoracic oncology specialist.

Treatment in thoracic oncology depends on the characteristics and dissemination of the tumours. A single specialist cannot treat all kinds and stages of thoracic tumours nowadays. An intense collaboration between disciplines is required. This is particularly important for borderline cases in which the best choice might be controversial or for the planning of multimodality treatments. It is reasonable that all experts involved should have enough knowledge of the collaborating specialties in order to understand each other. The thoracic oncology training should provide the learner with an insight into the disciplines complementary to their own. Therefore, the target audience for this curriculum are respiratory physicians, medical oncologists, radiation oncologists or thoracic surgeons The curriculum recommends the inclusion of the learner shadowing a specific specialist in the four leading thoracic oncology departments: respiratory medicine, thoracic surgery, medical oncology and radiation oncology. The minimum training time of 12 months is a compromise considering that a shorter period of time would probably not allow gaining an insight into the field. However, it is not realistic to prolong the training time for longer periods considering that the learner has already completed another specialty before. The Task Force therefore recommends training duration of up to 24 months.

Emphasising its multidisciplinary nature, this curriculum is not solely an ERS project. We actively sought out and accomplished collaboration with other societies in order to integrate the different points of view of the main specialties involved in the treatment of thoracic tumours. 
Thus, we created a document that is uniquely interprofessional and multidisciplinary. Consequently, we opened the possibility to obtain the accreditation as a thoracic oncology specialist for all physicians involved in the treatment of thoracic tumours.

We relied on the Delphi results of the syllabus content to be a good basis for the development and elaboration of the curriculum. Furthermore, feedback was sought and given by the national respondents as a form of validation by experts. The document remains a proposal of the present Task Force. The value of the curriculum will depend on the realisation of a thoracic oncology training programme, certification of training centres and the awarding of corresponding diplomas in the future. It is hoped that various structured educational programmes and educational resources will be created by the ERS, other professional societies and local institutions based on this curriculum.

In conclusion, herein we present the first truly interprofessional and multidisciplinary and, at present, the most detailed and actual thoracic oncology curriculum that has been created using current concepts of medical education. We hope that this curriculum will help to define the scope of advanced expertise in thoracic oncology and will be the basis for future training programmes.

\section{Acknowledgements}

The authors affiliations are as follows. F. Gamarra: Division of Respiratory Medicine, Klinikum Straubing, Straubing, Germany. J-L. Noël: European Respiratory Society, Lausanne, Switzerland. A. Brunelli: Dept of Thoracic Surgery, St James's University Hospital, Leeds, UK. A.-M.C. Dingemans: Dept of Pulmonology, Maastricht University Medical Centre, Maastricht, Netherlands. E. Felip: Hospital Universitari Vall d'Hebron, Barcelona, Spain. M. Gaga: 7th Respiratory Medicine Dept, Athens Chest Hospital, Athens, Greece. B.D. Grigoriu: University of Medicine and Pharmacy, Regional Institute of Oncology, Iasi, Romania. G. Hardavella: Dept of Respiratory Medicine, King's College Hospital, London, UK, and University College London, Lungs for Living Research Centre, London, UK. R.M. Huber: Division of Respiratory Medicine and Thoracic Oncology, Thoracic Oncology Centre Munich, University of Munich, Munich, Germany. S. Janes: Centre for Respiratory Research, University College
London, London, UK. G. Massard: Dept of Thoracic Surgery, University of Strasbourg, Strasbourg, France. P.M. Putora: Dept of Radio-oncology, Kantonsspital St. Gallen, St. Gallen, Switzerland. J-P. Sculier: Intensive Care and Thoracic Oncology, Institut Jules Bordet, Brussels Belgium. P.A. Schnabel: Institut für Allgemeine und Spzielle Pathologie, Saarland University, Homburg/Saar, Germany. S. Ramella: Dept of Radiation Oncology, Campus Bio-Medico University, Rome, Italy. D. Van Raemdonck: Dept of Thoracic Surgery, University Hospitals Leuven, Leuven, Belgium. A-P. Meert: Dept of Intensive Care and Thoracic Oncology, Institut Jules Bordet, Brussels, Belgium.

We would like to thank the ERS Leadership, Gernot Rohde (Education Council Chair) and Ernst Eber (HERMES Director), as well as the medical education specialists Erik Driessen and Griet Peeraer. We would also like to thank Sharon Mitchell and Alexandra Niculescu (European Respiratory Society), the ERS Thoracic Oncology Assembly, Dirk de Ruysscher and Jesper Grau Eriksen (European Society for Radiotherapy and Oncology), and Rolf Stahel Rainer Wiewrodt (European Society for Medical Oncology).

We would also like to thank the following national respondents: M. Nanushi (Albania), S. Taright (Algeria), H. Marshall (Australia), K. Kirchbacher (Austria), O. Burghuber (Austria), K.N. Uglyanitsa (Belarus), L. Bosquee (Belgium), M. Bakir (Bosnia/Herzegovina), M. Zamboni (Brazil), A. Kousoulova (Bulgaria), I. Novakov (Bulgaria), N. Bouchard (Canada), V. Ivcevic (Croatia), J. Skrikova (Czech Republic), J. Skrickova (Czech Republic), T.R. Rasmussen (Denmark), T. Laisaar (Estonia), J. Jaal (Estonia), R. Makitaro (Finland), M. Wislez (France), F. Barlesi (France), T. Blum (Germany), E. Stoelben (Germany), K. Gourgouliannis (Greece), J. Moldvay (Hungary), S. Jonsson (Iceland), A. Mohan (India), R. Morgan (Ireland), M. Kennedy (Ireland), Y. Schwarz (Israel), S. Elia (Italy), M. Beishembaev (Kyrgyzstan), A. Krams (Latvia), E. Danila (Lithuania), M. Schlesser (Luxembourg), S. Brincat (Malta), K. Skaug (Norway), J. Domagala-Kulawik (Poland), R. Sotto Mayor (Portugal), D. Jovanovic (Republic of Serbia), C. Paleru (Romania), D. Jovanovic (Serbia), P. Bezinec (Slovakia), E. Kavcova (Slovakia), N. Triller (Slovenia), I. Alfageme (Spain), G. Hillerdal (Sweden), L. Wannesson (Switzerland), S. Burgers (The Netherlands), H.J.M. Groen (The Netherlands), A. Erbaycu (Turkey), N. Lukavetskyy (Ukraine), P. Beckett (UK), M. Peake (UK), L. Kamman (USA) and O. loachimescu (USA).

\section{Supplementary material}

This article has supplementary material available from breathe.ersjournals.com 


\section{Conflict of interest}

$J$-L Noël is an employee of the European Respiratory Society. Further disclosures can be found alongside this article at breathe.ersjournals.com

\section{References}

1. Directive 2013/55/EU of the European Parliament and of the Council of 20 November 2013. http:// eur-lex.europa.eu/LexUriServ/LexUriServ.do?uri=0J: L:2013:354:0132:0170:en:PDF Date last accessed: March 14, 2016. Date last updated: December 28, 2013.

2. Garcia-Perez MA, Amaya C, Otero A. Physicians' migration in Europe: an overview of the current situation. BMC Health Serv Res 2007; 7: 201.

3. Gaga M, Powell CA, Schraufnagel DE, et al. An official American Thoracic Society/European Respiratory Society statement: the role of the pulmonologist in the diagnosis and management of lung cancer. Am J Respir Crit Care Med 2013; 188: 503-507.

4. Sculier JP, Vansteenkiste J, Schönfeld N, et al. Thoracic oncology in Europe: the ERS action plan by the Thoracic Oncology Assembly. Eur Respir J 2010; 36: 1227-1228.

5. Blum TG, Rich A, Baldwin D, et al. The European initiative for quality management in lung cancer care. Eur Respir J 2014; 43: 1254-1277.

6. Gamarra F, Boffetta P, De Ruysscher D, et al. Thoracic Oncology HERMES syllabus: setting the basis for thoracic oncology training in Europe. Eur Respir J 2013; 42: 568-571.

7. Meert A-P, Noël J-L, Boffetta P, et al. Thoracic Oncology HERMES: a European syllabus towards a harmonised education and training of Thoracic Oncology specialists. Breathe 2013; 9 : 381-392.

8. Oandasan I, Reeves S. Key elements for interprofessional education. Part 1: The learner, the educator and the learning context. J Interprof Care 2005; 19: Suppl. 1, 21-38.
9. lobst WF, Sherbino J, Cate OT, et al. Competency-based medical education in postgraduate medical education. Med Teach 2010; 32: 651-656.

10. Bluteau $\mathrm{P}$, Jackson $\mathrm{A}$ eds. Interprofessional education: Making it happen. London, Palgrave Macmillan, 2009.

11. Harden RM. AMEE Guide No. 21: Curriculum mapping: a tool for transparent and authentic teaching and learning. Med Teach 2001; 23: 123-137.

12. Bloom BS. Taxonomy of educational objectives; the classification of educational goals. 1st Edn. New York, Longmans, Green, 1956.

13. Adams NE. Bloom's taxonomy of cognitive learning objectives. J Med Libr Assoc 2015; 103: 152-153.

14. Swanwick T, ed. Understanding medical education: evidence, theory and practice. New York, John Wiley \& Sons, 2011.

15. Miller GE. The assessment of clinical skills/competence/performance. Acad Med 1990; 65: 9 Suppl, S63-S67.

16. Amin Z, Chong YS, Khoo HE. Objective Structured Clinical Examination. In: Practical guide to medical student assessment. Singapore, World Scientific, 2006; pp. 58-64.

17. Muss HB, Von Roenn J, Damon LE, et al. ACCO: ASCO core curriculum outline. J Clin Oncol 2005; 23: 2049-2077.

18. International Associations for the Study of Lung Cancer. Global Curricular Framework. www.iaslc.org/research-education/ global-curricular-framework Date last accessed: March 5, 2016.

19. Biggs J, Tang C. Applying constructive alignment to outcomes-based teaching and learning. In: Training Material for "Quality Teaching for Learning in Higher Education" Workshop for Master Trainers, Ministry of Higher Education, Kuala Lumpur. 2010; pp. 23-25. 